\title{
SOCIOLOGIA DAS CONSTITUIÇÕES: O CONSTITUCIONALISMO ENTRE O NORMATIVISMO E A TEORIA SISTÊMICA
}

\author{
Bernardo Leandro Carvalho Costa* \\ Leonel Severo Rocha **
}

Resumo: o presente trabalho tem como objetivos analisar as diferentes concepções do Constitucionalismo, bem como demonstrar a influência das matrizes jurídicas na observação do Direito Constitucional. Em um primeiro momento, far-se-á uma descrição da perspectiva tradicional de análise das Constituições. Após, por meio da metodologia sociológico-sistêmica, buscar-se-á evidenciar a insuficiência dessa observação para a compreensão do Constitucionalismo na globalização, apresentando os recentes estudos em Sociologia das Constituições como alternativa viável às insuficiências do normativismo. Em considerações finais, será evidenciada a necessidade de uma leitura sociológico-sistêmica do Direito Constitucional, com perspectiva de complementariedade em relação às tradicionais leituras do Constitucionalismo.

Palavras-chave: Constitucionalismo; Thornhill; Febbrajo; Teubner; Sociologia das Constituições; Teoria dos Sistemas Sociais;

\section{SOCIOLOGY OF CONSTITUTIONS: THE CONSTITUTIONALISM BETWEEN NORMATIVISM AND SYSTEMIC THEORY}

\begin{abstract}
Constitutionalism and shows the influence of legal matrices in Constitutional Law's observation. First, it will be done a description of the traditional analyze of the Constitutions. Second, through the sociologicalsystemic method will show the insufficiency of the observation before to understand the Constitutionalism in globalization process. After, as an alternative to the normativism insufficiencies will show the current studies in Sociology of Constitutions. In conclusion, trying to confirm the hypothesis, will show the necessity of a sociological-systemic observation of the Constitutional Law, complementing the traditional Constitutionalism perspective.
\end{abstract}

Keywords: Constitutionalism; Chris Thornhill; Febbrajo; Gunther Teubner; Sociology of Constitutions; Social Systems Theory;

\footnotetext{
* Mestrando em Direito Público pelo Programa de Pós-Graduação em Direito da Unisinos. Bolsista do CNPq. Membro do Grupo de Pesquisa Teoria do Direito (CNPq). Pesquisador nas áreas de Direito Constitucional e Sociologia Jurídica. E-mail: bernardoleandro@me.com.

** Doutor em Direito. Coordenador Executivo do Programa de Pós-Graduação em Direito da Unisinos. E-mail: Leonel@unisinos.br.
} 


\section{INTRODUÇÃO}

Em epistemologia jurídica, há três matrizes (diferentes modos) de observar o Direito: a analítica, a hermenêutica e a pragmático-sistêmica. A primeira matriz, a analítica, expressa a influência do pensamento de Kelsen (2009) no Direito, e os pressupostos teóricos que o normativismo apresenta. A terceira, a pragmático-sistêmica, sintetiza a influência da Teoria dos Sistemas Sociais de Luhmann (2007) na observação jurídica. (ROCHA, 2005).

Por meio dessa necessária divisão, buscar-se-á, no presente trabalho, demonstrar como no Direito Constitucional há o predomínio de leituras fundadas na matriz analítica e no normativismo, que vinculam a Constituição à figura do estado nacional como produtor exclusivo de normas jurídicas. Para tal, inicialmente será feita uma passagem pelo contexto de formação do constitucionalismo, fortemente vinculado à perspectiva dos estados nacionais.

Como contraponto, demonstrar-se-á o modo como os efeitos da globalização atingem os fenômenos jurídicos e consequentemente, diversos dos pressupostos que fundamentavam a tradicional Teoria Constitucional. Nesta parte, far-se-ão leituras de diferentes autores que se dedicam aos efeitos da globalização, com ênfase para as consequências no fenômeno jurídico.

Partindo dessa problemática, a hipótese levantada é a de que a emergência de leituras do Direito Constitucional fundadas em uma matriz pragmático-sistêmica, ciente dos efeitos da globalização na sociedade mundial, é imprescindível para a compreensão do constitucionalismo atual, ao mesmo tempo em que há um nexo de complementariedade entre as referidas perspectivas.

Com essa proposta, tem-se como objetivo fazer uma leitura de diferentes autores que se dedicam aos estudos em Sociologia do Constitucionalismo, possuindo como ponto em comum a matriz teórica pragmático-sistêmica. Nessa proposta, serão analisados os trabalhos de Febbrajo (2016), Neves (2009), Teubner (2016) e Thornhill (2011).

Trata-se de leitura imprescindível no contexto do atual estágio do Direito Constitucional, justificando-se pela necessária percepção dos influxos da globalização nas relações de poder; o que altera consideravelmente a tradicional estrutura do constitucionalismo.

Para tal, utilizar-se-á como metodologia a sociologia-sistêmica (LUHMANN, 2007) e como método de procedimento a técnica de documentação indireta, com revisão de bibliografia nacional e estrangeira. 
Em aportes conclusivos, com o intuito de confirmar a hipótese levantada, far-se-á um balanço entre a leitura tradicional do constitucionalismo e os recentes estudos em Sociologia das Constituições, evidenciando a complementariedade entre as duas perspectivas.

\section{CONSTITUCIONALISMO: PERSPECTIVA TRADICIONAL E SUA FUNDAMENTAÇÃO}

O constitucionalismo, em termos tradicionais, pode ser considerado como uma técnica jurídico-política de limitação do poder por meio de um documento único (Constituição). Tal perspectiva acompanha a Teoria Constitucional pelo menos a partir dos eventos revolucionários do século XVIII. (BOBBIO, 1987)

Um tópico que ilustra bem esse ponto de vista é a positivação, na Declaração dos Direitos do Homem e do Cidadão, de que "Qualquer sociedade em que não esteja assegurada a garantia dos direitos, nem estabelecida a separação dos poderes não tem Constituição (artigo 16).” (DECLARAÇÃO, 2018). Tal consideração vincula fortemente o Direito Constitucional à figura do Estado, considerado o centro produtor de normas jurídicas. Ademais, explicita a necessidade de um documento escrito para assegurar o que se passou a denominar de garantias constitucionais.

Esse pensamento é fortemente ligado ao paradigma adotado a partir do Tratado de Westfalia (1648), que estabeleceu o sistema político moderno, com o reconhecimento da existência de estados nacionais soberanos e com relações mútuas no cenário internacional. Cada Estado, como consequência, prescinde da delimitação dos elementos políticos que o constituem (separação de poderes é um dos exemplos), estabelecidos analiticamente por meio de uma Constituição.

A existência de uma Constituição, portanto, poderia ser verificada por meio da análise de um documento constitucional em que contasse - para ser considerada uma Constituição- a separação de poderes, constituindo um dos elementos político daquele referido Estado.

O ilustre jurista Carré de Malberg (1948) é um dos grandes expoentes dessa etapa do Direito Constitucional, em que a Constituição é observada com primazia na figura do Estado enquanto produtor exclusivo de normas jurídicas. Em sua obra clássica para

o Direito Constitucional, vincula diretamente o fenômeno do constitucionalismo à existência de um estado nacional com clara delimitação territorial. 
Já no século XX, a grande obra de Hans Kelsen (2009), ultrapassando as fronteiras do legalismo rumo à construção do normativismo, avançou em relação às propostas positivistas anteriores para concluir que a norma jurídica é um modo de observar o mundo. Todavia, em que pese os avanços apresentados pela obra de Kelsen (2003), a Teoria Constitucional por ele elaborada- mesmo considerando os relevantes debates com Carl Schmitt (1983) - permaneceu fortemente vinculada ao Estado. A divergência mais aparente entre os referidos autores é o controle da Constituição, seja por meio de um Tribunal Constitucional ou pelo presidente do Reich. Todavia, na questão epistemológica, há forte vinculação de ambos à matriz analítica, com os pressupostos teóricos do normativismo.

Há se de considerar a evolução da teoria kelseniana, principalmente as considerações acerca do surgimento de um Direito Internacional. Ademais, no contexto histórico em que a obra foi escrita, não seria exigível avanços no campo da territorialidade ou da observação do Direito a partir de outros campos sociais para além do Estado.

De fato houve, no âmbito da Teoria do Direito, um embate entre a perspectiva normativista de Kelsen e a proposta sociológica de observação do “Direito Vivo” de Ehrlich (1962). Este debate é retomado em estudos contemporâneos como o de Teubner (2016), com destaque à forte influência do pensamento sociológico de Ehrlich que o autor carrega. A Teoria Constitucional, todavia, sofreu forte influência no normativismo de Kelsen, corrente que acompanha as leituras majoritárias acerca do constitucionalismo.

Em uma perspectiva teórica, a influência de Kelsen, bem como dos autores positivistas que o precederam e seguiram a perspectiva do normativismo posteriormente, pode ser considerada uma matriz teórica: a matriz analítica.

Na divisão de Leonel Severo Rocha (2005), há três matrizes de fundamentação que sintetizam os diferentes modos de observar o Direito que são: a Analítica, a Hermenêutica e a Pragmático-Sistêmica.

Kelsen, a partir das influências que sofre de Kant (1999), é o grande influenciador da matriz analítica, que, em síntese: “[...] é uma matriz ainda bem centrada nos aspectos descritivos e estruturais do Direito, mantendo ainda, no tocante aos seus aspectos políticos, uma visão de neutralidade, por enquadrar-se no tipo de Estado liberal clássico, não interventor.” (ROCHA, 2009, p. 98)

Referida matriz, em que pese a importância no quadro da Teoria Constitucional, passou a apresentar diversas insuficiências a partir dos influxos na globalização no final do 
século XX, mormente por sua incapacidade de observar a complexidade social envolvida no entorno do sistema jurídico, que se expande para além das limitações territoriais do estado nacional, conforme se demonstrará a seguir.

\section{OS IMPACTOS DA GLOBALIZAÇÃO NO DIREITO CONSTITUCIONAL}

Com o intuito de fixar uma data próxima, pode-se considerar que a queda do muro de Berlim impulsionou o fenômeno globalizante, acarretando diversas alterações na sociedade, principalmente no que tange ao distanciamento das fronteiras geográficas dos estados nacionais. Mesmo assim, muitas das observações jurídicas permaneceram atreladas ao que na teoria social de denomina de nacionalismo metodológico. (BECK, 2007)

No campo do Direito, a existência de um campo normativo que transcende o monopólio de produção legislativa nacional, bem como de casos não passíveis de resolução a partir do ordenamento jurídico interno de cada país passaram a se apresentar como realidades a serem observadas pelos juristas.

Nesse sentido, destaca Garavito (2011, p. 73-74) que:

Os Estados compartilham hoje a função regulatória com uma ampla gama de instituições internacionais (desde a Organização Mundial do Comércio até a Corte Penal Internacional) e entidades privadas e ONGs (como as que participam no sistema monetário de códigos de conduta empresariais em matéria trabalhista ou ambiental). (tradução livre).

Ao lado do trabalho de Garavito, buscando uma construção teórica, podem-se citar os estudos empíricos de Schaffer (2012) e Berman (2013). Ademais, em busca de tipologias conceituais para observar o fenômeno da globalização no Direito são de grande relevância os estudos de Cover (1983) e Tamanaha (2008), sem esquecer os críticos, como Scheurmann (2008) e Habermas (2006).

Dezalay e Trubek (1996) destacam a influência dos advogados na transformação do Direito. Na medida em que esses atores são constantemente influenciados pela ordem global emergente, segundo o autor, consequentemente tentam modificar a ordem jurídica vigente. Nesse sentido, a partir de estudos de caos, demonstra a existência de espaço jurídico transnacional no interior da Comunidade Europeia. Com pressupostos de análise sociológica, utiliza o conceito de campo social- convertida para campo jurídico- para basear sua análise: 
Os campos jurídicos nacionais têm, de uma maneira ou de outra, sido sempre "penetrados" por influências extranacionais, e estruturas subnacionais de ordem privada ou pública que introduzem formas complexas de pluralismo jurídico que devem ser incorporadas em qualquer definição do campo [...] (DEZALAY; TRUBEK, 1996, p. 38).

Ponto interessante na obra dos autores é a chamada americanização do Direito Europeu, na medida em que passou a ser influenciado por advogados americanos atuantes no continente. Ademais, o fenômeno influenciou inclusive as faculdades de Direito na medida em que “A americanização da melhor e mais brilhante das faculdades de Direito da França minou ainda mais o antigo modelo europeu de produção jurídica acadêmica.” (DEZALAY; TRUBEK, 1996, p.79, tradução nossa). Esta é uma das constatações empíricas que leva os autores a apontarem a existência de um processo de transnacionalização do Direito.

Ciente de que a partir das constatações dos efeitos da globalização no Direito formamse duas correntes de pensamento: uma de cunho universalista e outra com destaque para a soberania dos estados nacionais, BERMAN (2013, p.1202, tradução nossa) busca uma alternativa aos conflitos propostos pelas duas perspectivas. Nesse diapasão, levando em conta o contexto da União Europeia, afirma que:

A ideia é propor um balanço entre a diferença entre cortes nacionais e legisladores por um lado e manter a "supervisão europeia" com poderes para a Corte Europeia de Direitos Humanos para dar a decisão final na medida em que verifica a compatibilidade de referidas decisões com a Convenção Europeia de Direitos Humanos. ${ }^{1}$

Na busca de definições conceituais, Tamanaha (2008, p.375) destaca a dificuldade de firmar uma definição de “Direito”, tendo em vista os diversos níveis normativos que contribuem para a construção jurídica na globalização: leis nacionais, transnacionais e internacionais de vários tipos. Nesse diapasão, com o intuito de apresentar uma construção histórica do que se concebe por "Direito", destaca como eventos importantes, a exemplo da perspectiva de Thorhill (2011) a redescoberta dos trabalhos de Aristóteles e do Código de Justiniano nos séculos XII e XIII, com grandes contribuições para a construção do Direito Público, principalmente por meio dos estudos do Direito Romano nas universidades.

\footnotetext{
${ }^{1}$ No original: "The idea here is to strike a balance between deference to national courts and legislators on the on hand, and maintaining "European supervision" that "empowers [the ECHR] to give final ruling” on whether a challenged practice is compatible with the Convention, on the other."
} 


\section{SOCIOLOGIA DAS CONSTITUIÇÕES: O CONSTITUCIONALISMO ENTRE 0 NORMATIVISMO E A TEORIA SISTÊMICA}

A adoção do Direito Romano na época compartilhou forte aceitação entre soberanos e representantes do comércio local, apresentando maior segurança jurídica quando comparado ao Direito Canônico e à pluralidade antes apresentada pelos costumes, contexto bem demonstrado no trabalho de Tamanaha (2008, p. 384, tradução nossa):

Em várias localidades havia um sistema dual, com várias e complexas combinações e influências mútuas. Coexistiam com o âmbito de um sistema legal abrangente, com processos judiciais estatais e normas instituídas pelo colonizador aplicadas principalmente em atividades econômicas e em assuntos de governo, enquanto costumes reconhecidos oficialmente ou instituições religiosas reforçavam normas locais.

Após demonstrar como o pluralismo jurídico envolve uma longa discussão histórica, marcada por diversos fatos que representaram ora a fragmentação jurídica e ora a consolidação por meio da tentativa de aglutinar o Direito em uma fonte única (Direito Romano ou posteriores processos de codificação), Tamanaha (2008, p. 386) passa a demonstrar como essa discussão foi retomada no final do século XX, com a consideração dos efeitos da globalização.

Como outros autores na área, na construção histórica é demonstrada a importância do Tratado de Westphalia (1648), que dividiu a Europa em diferentes territórios dotados de soberania, dando início ao que mais tarde se tornaria a divisão em estados nacionais. (TAMANAHA, 2008, p. 379). Voltando ao contexto da globalização, destaca que os estados, antes soberanamente divididos em territórios, perderam consideravelmente o poder local que possuíam, com fortes sinais de diminuição das tradicionais funções estatais. (TAMANAHA, 2008, p. 387).

Esse pluralismo é representado por diversas dimensões. Por um lado, o pluralismo jurídico internacional (considerando o Direito Internacional) é observado por meio da existência de múltiplos tribunais a nível internacional, além de distintos corpos de normas legais para a regulação de temas específicos, como Direitos Humanos, Propriedade Intelectual, crimes contra a humanidade, entre outros. Por outro lado, é cada vez mais constante a incorporação de direito internacional em diferentes níveis pelos tribunais dos estados. (TAMANAHA, 2008, p. 387). Por essas circunstâncias, levando-se em conta os influxos da globalização, é cada vez mais difícil achar uma definição de "Direito":

Direito é um “conceito popular”, ou seja, Direito é o que as pessoas e grupos sociais consideram como „direito". Isso pode ser formulado em termos de uma categoria científica singular ao longo do tempo e em diferentes lugares 
pessoas observam o Direito de diferentes formas. O Direito Estatal é correntemente o paradigma exemplificativo de Direito, mas, em várias épocas e lugares diversos, incluindo hoje, pessoas consideram como Direito: Direito Internacional; Direito Costumeiro; versões de Direito Religioso; lex mercatoria, ius commune; direito natural, entre outros. ${ }^{2}$ (TAMANAHA, 2008, p.396, tradução nossa).

Shaffer (2012, p. 04), outro dos autores acima citados, descreve bem os efeitos da globalização no contexto jurídico ao demonstrar o processo de construção de um Direito transnacional. A migração de fontes jurídicas em diversos níveis ocorre principalmente por meio de citações de direito estrangeiro (de outros países) e direito internacional no contexto das cortes federais, a exemplo do que ocorre nos Estados Unidos. Não necessariamente, como bem destaca, a citação desse tipo de legislação é oriunda de tratados internacionais entre países. Muitas das vezes, o processo de transnacionalização ocorre de modo inconsciente, como um verdadeiro feedback entre ordens jurídicas.

Neste processo, intensificado após a queda do Muro de Berlim, é possível observar sociologicamente diversos exemplos de transnacionalização, operados com o auxílio das tradicionais concepções de direito internacional, de atores privados em seus âmbitos de autoorganização, de uma nova lex mercatoria e de diálogos transgovernamentais para a regulamentação de pontos comuns. Neste último caso, cita como exemplo a pressão internacional para que países adotem medidas efetivas no combate à lavagem de dinheiro. Em específico, cita o relevante trabalho de Maíra Rocha Machado (2012), analisando sociologicamente os efeitos dessas pressões no Brasil e na Argentina.

Em uma proposta de conceituação, Shaffer (2012, p.4, tradução nossa) define o Direito transnacional como:

[...] uma construção transnacional e um fluxo de normas legais, com ênfase na produção transnacional de normas legais e formas institucionais em suas peculiaridades, com migração para além das fronteiras dos estados nacionais, independentemente se as atividades para as quais se destinam sejam de caráter transnacional ou meramente nacionais. ${ }^{3}$

\footnotetext{
${ }^{2}$ No original: "Law is a „folk concept" that is, law is what people within social groups have come to see and label as ,law". It could not be formulated in terms of a single scientific category because over time and in different places people have seen law in different terms. State law is currently the paradigm example of law, but at various times and places, including today, people have considered as law: international law; customary law; versions of religious law; the lex mercatoria; the ius commune; natural law and more.”

${ }^{3}$ No original: "[...] Transnational Law as Transnational Construction and Flow of Legal Norms, in contrast, focuses on the transnational production of legal norms and institutional forms in particular fields and their migration across borders, regardless of whether they address transnational activities or purely national ones.”
} 


\section{SOCIOLOGIA DAS CONSTITUIÇÕES: O CONSTITUCIONALISMO ENTRE 0}

NORMATIVISMO E A TEORIA SISTÊMICA

Após essa definição conceitual, Shaffer (2012, p.10) apresenta empiricamente diversos estudos que comprovam o fenômeno apontado. Para além do já citado acerca da lavagem de dinheiro (MACHADO, 2012) são outros exemplos: a educação primária e os serviços municipais de regulação da água; ambos casos de âmbito local que sofreram influxos de perspectivas jurídicas transnacionais.

Tais constatações são feitas a partir de observações da influência de atores transnacionais, sejam redes ou instituições transnacionais, cujos atores, públicos e privados, atuam na difusão de normas legais. Referidas influências estão presentes em várias áreas do Direito (SHAFFER, 2012, p. 12). Todavia, uma vez que envolvem constantemente a superação das fronteiras dos estados nacionais, não deixam de ser principalmente um fenômeno constitucional a ser analisado.

Nessa linha, em termos de Direito Constitucional, os influxos da globalização têm provocado grandes alterações, mormente no que tange a modificações na ideia de Constituição, anteriormente vinculada à figura dos estados nacionais, conforme destacado acima. Tal perspectiva é observada por Teubner (2003), que retoma alguns dos postulados do Direito Vivo de Ehrlich (1962) na tradicional discussão com Kelsen, mas cuja principal matriz teórica é a pragmático-sistêmica, com forte influência nas concepções de Luhmann (2015).

Ao lado de Teubner, outros autores importantes têm se debruçado a observações do Direito Constitucional na globalização. Em comum, possuem a Teoria dos Sistemas Sociais de Luhmann (2015) como ponto de partida. Nesse diapasão, destacam-se os recentes trabalhos de Febbrajo (2016), Neves (2009) e Thornhill (2011), que contribuem para o surgimento de uma nova área de estudos no Direito: a Sociologia do Constitucionalismo.

\section{A SOCIOLOGIA DO CONSTITUCIONALISMO}

De um modo geral, os efeitos da globalização alteraram tradicionais concepções em matéria de Direito Constitucional, mutações percebidas em obras de relevantes autores sobre o tema.

Na Europa, a obra de Canotilho (2008) evoluiu para considerar o fenômeno europeu recente denominado de interconstitucionalidade, representando uma circunstância que expressa sobremaneira os influxos globalizantes no Direito. Tal etapa demonstra a alteração na obra do 
autor, antes fortemente vinculado à perspectiva de um Direito Constitucional fortemente vinculado aos estados nacionais. (CANOTILHO, 1982).

Nos Estados Unidos, o trabalho de Bruce Ackermann (2007) evidencia a necessidade de superação de modelo jurídico-constitucional "provincialista", para observar os fenômeno da globalização nas relações de poder.

Para além dos diversos autores que adicionaram aos seus trabalhos anteriores as considerações acerca do fenômeno da globalização no Direito Constitucional, há uma série de novos trabalhos que evidenciam a necessidade de uma observação sociológica do constitucionalismo, partindo de uma análise fundada na matriz pragmático-sistêmica para a compreensão das relações de poder em uma sociedade globalizada.

Com pressupostos teóricos vinculados à Teoria dos Sistemas Sociais de Luhmann (2015), os recentes trabalhos em Sociologia do Constitucionalismo adequam as tradicionais leituras do Direito Constitucional aos influxos da globalização. Em comum, pode-se citar a desvinculação da produção jurídica à figura dos estados nacionais.

Nessa perspectiva, Febbrajo (2016) faz uma síntese dos estudos acerca da Sociologia do Constitucionalismo, destacando a já conhecida discussão entre Kelsen e Ehrlich. No embate, retoma alguns dos pressupostos do "Direito Vivo" para compreender a atual fragmentação jurídica. Entre outros pontos, partindo da diferença entre a perspectiva normativa (Kelsen) e do Direito Vivo (Ehrlich), afirma que tal separação serve para elucidar a diferença entre as atuais Constituições formais (estatais) e Constituições materiais (vivas), criadas de modo autônomo por diversas instituições e diferentes setores da sociedade.

Em linha semelhante à da separação em matrizes jurídicas feita por Rocha (2005), Febbrajo (2016, p. 18) destaca que confluem ao menos três perspectivas de observação do Direito, com destaque para a normativa, com influência kelseniana. A função da Sociologia do Direito nesse cenário é de reinterpretar essas concepções. Nessa perspectiva, em síntese:

\begin{abstract}
A imagem tranquilizadora, fornecida pelo positivismo jurídico, de uma Constituição posta no vértice das normas do direito é assim corrigida por uma representação policêntrica em que os fatores sociais de diversa natureza desempenham um papel importante ao lado dos fatores jurídicos, e o direito é explicado com e na sociedade, ao invés de somente com o direito.
\end{abstract}

Divisão semelhante à de Febrajjo é demonstrada por Thornhill (2011), que dedica a primeira de suas obras acerca da Sociologia do Constitucionalismo para traçar uma linha histórica da Teoria Constitucional. Neste trabalho, após destacar a importância das categorias 


\section{SOCIOLOGIA DAS CONSTITUIÇÕES: O CONSTITUCIONALISMO ENTRE 0 NORMATIVISMO E A TEORIA SISTÊMICA}

tradicionais da sociologia, como os trabalhos de Durkheim (1978), Karl Marx (MARX, 1991) e Max Weber (1991), Thornhill assume uma postura sociológico-sistêmica, com influências em Luhmann e Parsons (1974), para propor o funcionalismo histórico como método para observar a formação das Constituições. Com essa proposta, afirma que muito antes dos primeiros documentos constitucionais escritos já havia movimentos constitucionais no sentido sociológico-sistêmico.

Na perspectiva de Luhmann (2015), da qual parte Thornhill para construir o funcionalismo-histórico, as Constituições são acoplamentos estruturais entre os sistemas da Política e do Direito. Nesse sentido, cada decisão política deve estar fundamentada no código do Sistema do Direito (Direito/Não Direito) como requisito de sua legitimidade. Ao mesmo passo, o Sistema do Direito necessita do meio simbolicamente gerado pelo Sistema da Política (poder) para dar cumprimento a suas decisões. A formação dos estados pressupõe essa distinção: “A formação dos estados como instituições autônomas, diferenciadas e dotadas de poder somente ocorre por meio da interpenetração do Direito nas instituições políticas. O Direito formal é precondição da formação estatal.”4 (THORNHILL, 2011, p. 59) (tradução livre)

A partir dessa concepção, Thornhill (2011, p. 25) destaca a existência desses movimentos constitucionais já na Idade Média, por meio do que denomina de "Medieval Constitutions”, uma vez que diferentes instrumentos jurídicos eram invocados nas decisões políticas dos medievos nos séculos XII e XIII. Nessa linha, propõe uma construção histórica, que vai até as diferentes ondas constitucionais do século XX, com final nas constituições criadas após a queda do Muro de Berlim.

Em recente obra (THORNHILL, 2016), parte da observação da penetração de normas internacionais em decisões de tribunais nacionais para demonstrar a existência de Constituições Transnacionais no atual cenário de Direito globalizado. Como pressuposto, invoca novamente a separação entre as perspectivas normativa e sociológica de observação do constitucionalismo, a exemplo das divisões de Febbrajo (2016) e Rocha (2005).

Nessa divisão, seleciona as concepções clássicas do Direito Constitucional, a exemplo da fundação norte-americana, como um ponto de partida para essa separação, evidenciando a

\footnotetext{
${ }^{4}$. No original: "The formation of states as differentiated autonomous institutions applying increasingly positive reserves of power only occurred because of the interpenetration of political institutions with law. Formal law was the primary precondition of statehood."
} 
importância da Sociologia das Constituições na leitura de eventos históricos também: “[...] constituições clássicas aparecem como documentos normativos únicos em que, nas palavras de Alexander Hamilton, ‘sociedades de homens’ estabelecem a fundação do bom governo, usando capacidade racional de reflexão e escolha.”5 (THORNHILL, 2011, p. 31) (tradução livre).

Portanto, as diferentes vertentes da Sociologia do Constitucionalismo aqui demonstradas possuem como posição inicial a distinção em relação à perspectiva normativa de observação do Direito. A partir dessa diferença, sabendo que o início de sua construção histórica é feita em momento de ausência de documentos únicos e escritos (Idade Média), mas que o ponto de chegada (final do século XX) encontra longos textos normativos, Thornhill (2011, p. 32), a fim de encontrar uma compatibilização entre as duas perspectivas, afirma que:

Constituições clássicas podem ser observadas não apenas como acordos normativos literais, mas como instrumentos de adaptação em que, com diferentes níveis de deliberação, sociedades consolidam sua diferenciação funcional, elaboram e preservam a inclusão política. ${ }^{6}$ (tradução livre).

A observação das Constituições, portanto, em uma perspectiva sociológico-sistêmica, não é considerada de maneira analítica ou normativista, por meio da análise de documentos constitucionais, mas a partir das pontes de conexão entre os sistemas da Política e do Direito, o que Luhmann (2015) denomina de acoplamento estrutural.

Na perspectiva de Thornhill (2011), que faz um levantamento histórico acerca desse fenômeno, no momento de formação de modelos de organização política que antecedem a formação dos estados nacionais, cada decisão política precedia necessariamente de um fundamento jurídico. Nesse sentido, a cada tentativa de unificação política é possível observar como historicamente formaram-se os acoplamentos estruturais entre Política e Direito, independentemente da fonte jurídica invocada para legitimar as decisões do Sistema da Política. Esses fenômenos, na perspectiva de Thorhill, representam o que concebe- em linha semelhante a Luhmann- como Constituições.

\footnotetext{
${ }^{5}$ No original: "In much inquiry into global constitutional law, classical constitutions appear, simply and literally, as single normative documents, in which, in Alexander Hamilton's words, 'societies of men' establish the foundation of 'good government', using rational capacities of 'reflection and choice' (Madison, Hamilton and Jay 1987 [1787-88]:87), and in which states derive legitimacy from the aggregated will of national society."

${ }^{6}$ No original: "Classical constitutions can be seen, not solely as literally objectivized normative agreements, but as adaptive instruments, through which, beneath the level of practical deliberation, societies consolidated their functional exchanges, and through which, above all, they learned to elaborate and preserve structures of general political inclusion."
} 


\section{SOCIOLOGIA DAS CONSTITUIÇÕES: O CONSTITUCIONALISMO ENTRE 0 NORMATIVISMO E A TEORIA SISTÊMICA}

A título de exemplo histórico, Thornhill (2011, p. 43) cita o empenho em aplicar uma regularidade legal ao longo do final do século XX e início do século XIII no Sacro Império Romano-Germânico. Para tal, a fim de superar a pluralidade de jurisdições privadas e privilégios típicos do feudalismo, a invocação de princípios do Direito Romano foi o início da construção de um Direito Público autônomo.

Tal evento, na perspectiva aqui observada, pode ser considerado como um típico fenômeno constitucional, consistindo no acoplamento estrutural de dois sistemas em formação (Direito e Política), na medida em que, com o intuito de unificar a aplicação do Direito, cada decisão política, como critério de legitimação, invocava princípios do Direito Romano como item de fundamentação.

Com o exemplo desse fenômeno, muitos outros sucederam na linha histórica a construção de Constituições, muito antes da formação dos estados nacionais e da elaboração dos documentos constitucionais unificados no século XVIII. Levando em consideração essa perspectiva sociológica, são elencadas as características de uma Constituição:

$\mathrm{Na}$ perspectiva aqui apontada, a Constituição possui as seguintes características: é uma ordem legal impactando no exercício do poder político que: (a) contém o estabelecimento de uma presunção efetiva de Direito Público de acordo com princípios ou convenções consideradas Direito, que (a) não podem (sem discussão pública prévia) serem suspensos; (b) pode compelir ou restringir notoriamente a utilização do poder em funções públicas ou privadas; (c) atribui poderes no interior do Estado e abrange alguma forma de representação popular considerada importante politicamente para todos os setores da sociedade; e (d) expressa uma distinção legal entre o Estado e pessoas que assumem temporariamente papéis políticos para o cumprimento de funções estatais. ${ }^{7}$ (THORNHILL, 2011, p. 10-11) (tradução livre).

A perspectiva de Thornhill (2011), portanto, a exemplo das tipologias descritas por Febbrajjo (2016), em que pese a diferenciação em relação a categorias tradicionais do Direito Constitucional, precedem de uma observação da relação do Sistema do Direito, cuja organização central são os tribunais, e o Sistema da Política, que tem no Estado sua organização

\footnotetext{
${ }^{7}$ No original: "On the account offered here, in sum, a constitution has the following features. It is a legal order impacting on the exercise of political power that: (a) contains an effectively established presumption of public rule in accordance with principles or conventions, expressed as law, that (a) cannot easily (i.e. without societally unsettling controversy) be suspended; (b) is designed to constrain or restrict egregiously mandatory use of pwer in both public and private functions; (c) allocates powers within the state itself, and comprises some form of popular/political representation in respect of questions perceived as possession importance for all politically relevant sectors of society; snd (d) express a legal distinction between the form of the state and those persons assuming authority to borrow and enforce the power stored within the state."
} 
referência. A partir dessas concepções, referidos autores apresentam os diferentes níveis de observação do constitucionalismo na globalização, cuja referência, em que pese não seja o abandono do Estado, é a não vinculação aos estados nacionais com suas limitadas constituições analíticas.

Em tom semelhante, Neves (2009) sustentou a necessária conversação constitucional em diferentes níveis; o que denominou de Transconstitucionalismo. Nesse sentido, tendo em vista os influxos da globalização, considerando que há problemas comuns que ultrapassam as fronteiras dos estados nacionais, cada vez mais é necessário que tribunais de diferentes níveis (nacional, supranacional ou transnacional) utilizem referências externas aos seus tradicionais pressupostos normativas para decidirem casos complexos que se apresentam.

A título de exemplo, um tribunal situado no Brasil, ao se deparar com um caso que transcende as fronteiras do estado brasileiro, como lavagem de dinheiro oriundo do Brasil no exterior, apurada mediante troca de informações entre países, necessariamente o tribunal é incentivado a cada vez mais utilizar referências que ultrapassem o direito positivo nacional para decidir a questão. Nessa busca normativa, citam-se como exemplos a legislação internacional sobre o assunto e decisões de tribunais de diferentes níveis, invocados como ratio decidendi pelo tribunal brasileiro. (NEVES, 2009, p. 118) Há de se destacar que o problema citado como exemplo pode envolver diferentes países, bem como atores (empresas transnacionais) situadas em diferentes territórios, fato que tem gerado constantes discussões na Teoria Geral do Delito (SCHUNEMANN, 2018).

Passadas as considerações sobre Febbrajo, Thornhil e Neves, é interessante a síntese feita por Vesting (2015, P. 251) acerca das conclusões possíveis a partir dos pontos em comum apresentados nas perspectivas acima citadas:

Essa remissão de questões metodológicas a questões conteudísticas torna-se ainda mais importante quando as colisões entre "níveis jurídicos" não conseguem mais pressupor uma estrutura piramidal, e.g., nos casos em que os tribunais (e a administração pública) são confrontados com um sistema policêntrico desprovido de hierarquias decisórias claras, como, por exemplo, no "triângulo" Direito constitucional-Direito europeu-Direito internacional.

Diferente perspectiva, mas ainda vinculada às mudanças no Direito Constitucional é apresentada por Teubner. Desde a publicação de “Global Bukowina” (TEUBNER, 2008), em que retoma a discussão entre Kelsen e Eherlich, destaca que há um deslocamento sucessivo dos pontos de formação do Direito, antes atrelados aos estados nacionais (parlamentos, tribunais e 


\section{SOCIOLOGIA DAS CONSTITUIÇÕES: O CONSTITUCIONALISMO ENTRE 0 NORMATIVISMO E A TEORIA SISTÊMICA}

tratados no Direito Internacional) para atores envolvidos em uma autoprodução normativa, em seus diferentes exemplos (lex mercatoria, FIFA, internet).

Nesse sentido, por meio de fontes autônomas de atores privados desvinculados aos tradicionais elementos do Estado, Teubner (2016) afirma que não é possível afirmar com veemência a existência de tradicionais Constituições, mas sim de diversos fragmentos constitucionais, ou seja, de diferentes centros de produção normativa, dotados de poder (código do Sistema da Política) e que tomam decisões a nível mundial. Tal circunstância, na perspectiva de Teubner (2016), afeta diretamente as concepções tradicionais do Constitucionalismo.

A principal divergência de Teubner em relação aos autores citados anteriormente possui como fonte sua forte influência no Direito Privado, ponto bem explorado por Priban (PRIBAN, 2012). Todavia, não o exclui da linha de pensadores em Sociologia do Constitucionalismo, afinal, o ponto de partida para a sua observação é a incidência do fenômeno da globalização no Direito, que tem como um dos resultados a formação de Constituições autônomas nos diferentes sistemas sociais.

Em síntese, os autores acima citados, a partir das diferentes concepções que contrariam a tradicional perspectiva do Direito Constitucional, representam os recentes estudos em Sociologia do Constitucionalismo, tendo como base teórica comum a Teoria dos Sistemas Sociais de Luhmann. (2015).

\section{CONSIRAÇÕES FINAIS}

Como se viu ao longo do trabalho, há uma concepção tradicional de observação do constitucionalismo, que vincula a caracterização de uma Constituição à existência de um documento único, vinculado à figura do Estado nacional como produtor único do Direito. Tratase de corrente surgida principalmente após os eventos revolucionários do século XVIII. Um dos autores que bem expressa tal movimento é Carré de Malberg (1948), considerado um dos clássicos do Direito Constitucional.

Na linha história da teoria jurídica, a obra de Kelsen no século XX influenciou fortemente as diferentes áreas do Direito. A corrente kelseniana foi efetivamente a que mais influenciou a tradição jurídica, considerando-se o histórico debate entre normativismo (KELSEN, 2009) e direito vivo (EHRLICH, 1962), que contrapôs elementos da analítica e da 
sociologia jurídica. Isso não foi diferente com a Teoria Constitucional, que passou a ser defendida como objeto de estudos por Carl Schmitt (1983).

Ao mesmo passo em que se demonstrou essa origem das concepções tradicionais do constitucionalismo, o presente artigo afirmou que há três matrizes teóricas que sintetizam as leituras possíveis do fenômeno jurídico: a analítica (normativismo), a hermenêutica e a pragmático-sistêmica. (ROCHA, 2009)

A partir dessa divisão, foi possível concluir que há um predomínio de leituras feitas a partir da matriz analítica, típica do normativismo kelseniano, nas observações do Direito Constitucional. (ROCHA, 2009).

Todavia, a partir das inevitáveis constatações dos efeitos da globalização sobre o Direito, fez-se imprescindível que a Teoria Constitucional apresenta-se uma nova leitura do constitucionalismo, considerando a desvinculação -cada vez mais aparente- entre as Constituições e os estados nacionais.

A partir dessa problemática, os estudos em Sociologia do Constitucionalismo apresentam observações que partem de uma matriz pragmático-sistêmica, apta a demonstrar os efeitos da globalização nas relações entre os sistemas da Política e do Direito, retomando -além da forte linha sistêmica que possuem- alguns dos pressupostos da sociologia jurídica expressados no debate de Ehrlich (1962) com Kelsen (2009).

Apresentada essa nova linha de estudos (a Sociologia das Constituições), conclui-se que é a mais apta a descrever o Constitucionalismo atualmente, mormente por não sonegar os influxos da globalização no fenômeno jurídico. Ao mesmo tempo, todavia, não despreza as tradicionais concepções do Direito Constitucional. A Sociologia das Constituições, portanto, consoante expresso no título do presente trabalho, propõe-se a analisar o Constitucionalismo entre o normativismo (matriz analítica) (ROCHA, 2009) e a teoria sistêmica (matriz pragmático-sistêmica) (ROCHA, 2009), evidenciando a complementariedade entre as referidas perspectivas de observação do fenômeno constitucional.

\section{REFERÊNCIAS}

BECK, Ulrich. The Cosmopolitan Condition: Why Methodological Nationalism. In. Theory, Culture e Society, 24, pp. 286-290. 2007. 
BERMAN, Paul Schiff. Global Legal Pluralism. A Jurisprudence of Law Beyond Borders.

Cambridge: Cambridge University Press, 2013.

BOBBIO, Norberto. Estado, governo e sociedade: por uma teoria geral da política. Tradução Marco Aurélio Nogueira. Rio de Janeiro: Paz e Terra: 1987.

COVER, Robert. Nomos and Narrative, Harvard Law Review, n.97, v.5, pp. 4-68. 19831984.

DECLARAÇÃO DOS DIREITOS DO HOMEM E DO CIDADÃO. MINISTÉRIO

PÚPLICO FEDERAL. Disponível em: < http://pfdc.pgr.mpf.mp.br/atuacao-e-conteudos-deapoio/legislacao/direitos-humanos/declar_dir_homem_cidadao.pdf $>$. Acesso em: 17 mar. 2018.

DURKHEIM, Émile. Da divisão do trabalho social. São Paulo: Abril Cultural, 1978.

EHRLICH, E. Fundamental Principles of the Sociology of Law. New York: Russel e Russel. 1962.

FEBBRAJO, Alberto. Sociologia do Constitucionalismo: Constituição e Teoria dos Sistemas. São Paulo: Juruá, 2016.

GARAVITO, César Rodríguez. Navegando la globalización: un mapamundi para el estudio y la práctica del derecho en América Latina, in: GARAVITO, César Rodriguez. El derecho en América Latina: un mapa para el pensamiento jurídico del siglo XXI, Mexico DF: Siglo Vienteuno Editores, 2011. p. 73-74.

HABERMAS, Jürgen. A constitucionalização do direito internacional ainda tem uma chance? In. HABERMAS, Jürgen. O Ocidente Dividido. Rio de Janeiro: Tempo Brasileiro, 2006.

KANT, Immanuel. Crítica da razão pura. São Paulo: Nova Cultural, 1999.

KELSEN, Hans. Jurisdição constitucional. São Paulo: Martins Fontes, 2003.

Teoria Pura do Direito. 8. ed. São Paulo: Martins Fontes, 2009.

LUHMANN, Niklas. La sociedad de la sociedad. Traducción de Javier Torres Nafarrate. México: Herder, 2007.

O direito da sociedade. São Paulo: Martins Fontes, 2015.

MALBERG, R. Carré De. Teoria general del estado. Mexico: Fondo de Cultura Económica, 1948.

MARX, Karl. Capital: a critique of political economy. London: Penguin Books, 1991.

NEVES, Marcelo. Transconstitucionalismo. São Paulo: Martins Fontes, 2009. 
PARSONS, Talcott. O sistema das sociedades modernas. São Paulo: Pioneira, 1974.

PRIBAN, Jiri. Constitutionalism as Fear of the Political? A Comparative Analysis of Teubner's Constitutional Fragments and Thornhill's A Sociology of Constitutions. Journal of Law and Society, 2012.

ROCHA, Leonel Severo. Epistemologia jurídica e democracia. São Leopoldo: Unisinos, 2005.

; AZEVEDO, Guilherme de. Notas para uma teoria da organização da decisão jurídica autopoiética. Revista de Estudos Constitucionais, Hermenêutica e Teoria do Direito (RECHTD). São Leopoldo, RS, ano 4, v. 2, jul./dez. p. 193-213, 2016. Disponível em: $<$ http://revistas.unisinos.br/index.php/RECHTD/article/view/rechtd.2012.42.09>. Acesso em: 10. Out. 2016.

. Observações sobre a observação luhmanniana. In. ROCHA, Leonel Severo; KING, Michael, SCHWARTZ, Germano. A verdade sobre a autopoiese no direito. Porto Alegre: Livraria do Advogado, 2009. p. 11-39.

. Tempo, Direito e constituição. In. SCHWARTZ, Germano; ROCHA; Leonel Severo (Org.). Sociologia sistêmico- autopoiética das constituições. Porto Alegre: Livraria do Advogado, 2015. p. 137-159.

SCHAFFER, Gregory. Transnational Legal Process and State Change: Opportunities and Constrainst. Law e Social Inquiry, v.37, I.2, pages 229-264, Spring, 2012.

SCHERUERMANN, William. Franz L. Neumann: Legal Theorist of Globalization?. In: Frankfurt School Perspectives on Globalization, Democracy and the Law. London: Routledge, 2008.

SCHMITT, Carl. La defensa de la constitucion: Estudio acerca de las diversas especies y posibilidades de salvaguardia de la constitucion. Madrid: Tecnos, 1983.

SCHÜNEMANN, Bernd. El próprio sistema de la teoría del delito. Revista para análisis del derecho (InDret), $\mathrm{n}^{\circ}$ 1, 2008. Disponível em: < www.indret.com/pdf/505.pdf.com>. Acesso em: 29 mar. 2018.

TAMANAHA, Brian Z. Undestanding Legal Pluralism: Past to Present, Local to Global. Sydney Law Review, pp. 375-411. 2008.

TEUBNER, Gunther. Direito, sistema e policontexturalidade. Piracicaba: Unimep, 2005.

. “Global Bukowina: Legal Pluralism in the World-Society”, in. TEUBNER, Gunther (ed). Global Law Without a State. London: Dartsmounth, 2008.

A Bukowina Global sobre a emergência de um pluralismo jurídico internacional. Impulso. Revista de Ciências Sociais e Humanas. V. 14, pp. 9-32, 2003. 


\section{SOCIOLOGIA DAS CONSTITUIÇÕES: O CONSTITUCIONALISMO ENTRE 0 NORMATIVISMO E A TEORIA SISTÊMICA}

. Fragmentos constitucionais: constitucionalismo social na globalização. São Paulo: Saraiva, 2016.

O direito como sistema autopoietico. Lisboa: Fundação Calouste Gulbenkian, 1993.

Societal Constitutionalism: Alternatives to State-Centred Constitutional Theory?, in.

JOERGES, C. et al. (Org.), Transnational Governance and Constitutionalism. Oxford:Hart Press, 2004.p. 3-29.

THORNHILL, Chris. A Sociology of Constitutions: Constitutions and State Legitimacy in Historical-Sociological Perspective. New York: Cambridge University Press, 2011.

A sociology of Transnational Constitutions: social foundations of the post-national legal structure. London: Cambrigde, 2016.

National sovereignty and the constitution of transnational law: a sociological approach to the classical antinomy. Transnational Legal Theory: a quarterly journal. [Sl.], V.3, n.4. p. 416, 2012.

Political legitimacy: a theoretical approach between facts and norms. Constellations, [S.l.] v.18, n.2, p.135-169, 2011.

Rights and constituent power in the global constitution. International Journal of Law in Context. [S.1], v.10, n.3, p. 6, 2014.

. The autonomy of the political: a social theoretical response. Philosophy and Social Criticism. [S.l.], v. 35, n.6, p. 705-735, 2014.

The evolution of modern states. International Studies Review, [S.l.], v.14, n.1, p. 463-465, 2012.

Towards a historical sociology of constitutional legitimacy. Theory and Society. [S.l.]. V. 37, n. 2, p. 161-197, 2008.

VESTING, Thomas. Teoria do Direito: uma introdução. São Paulo: Saraiva, 2015.

WEBER, Max. Economia e sociedade: fundamentos da sociologia compreensiva. Brasília: Universidade de Brasília, 1991 